\title{
Participação de mulheres no cenário eleitoral brasileiro: questões e explicações na ciência política
}

\author{
Women's participation in the Brazilian electoral scenario: questions and \\ explanations in political science
}

\section{Priscila Lapa ${ }^{1}$ \\ Jamerson Kemps ${ }^{2}$}

Resumo: Nas discussões sobre a presença feminina na esfera política são comuns argumentos que explicam a reduzida participação de mulheres em razão de condicionantes estruturais, demonstrando que nos padrões sociais estabelecidos estão localizados os determinantes causais desse fenômeno, de modo que a dominação dos homens sobre as mulheres no espaço privado se reproduziria no espaço público. Este artigo busca apontar como essa discussão está presente nas explicações acerca da eleição de mulheres no cenário político brasileiro, apresentando os principais argumentos utilizados à luz da Teoria Social. Apresenta também de que maneira a literatura acerca dos determinantes do voto na Ciência Política formula análises sobre a escolha de mulheres nas eleições brasileiras, levando em conta que os estudos contemporâneos amparam-se em diversos pressupostos do neoinstitucionalismo e da Teoria da Escolha Racional. Nessa perspectiva, este trabalho intenta apresentar novas perspectivas para se debater a eleição de mulheres que começam a surgir a partir das lacunas existentes nas análises tradicionais do fenômeno.

\footnotetext{
${ }^{1}$ Doutoranda em Ciência Política no Programa de Pós-Graduação em Ciência Política da Universidade Federal de Pernambuco. Jornalista, mestre em Ciência Política (UFPE, 2007). Área de concentração: Estudos eleitorais. E-mail: lapapriscila@gmail.com

2 Doutorando em Sociologia no Programa de Pós-Graduação em Sociologia da Universidade Federal de Pernambuco. Professor, licenciado em História e mestre em Antropologia, ambos pela UFPE.
}

Latitude, Vol. 8, no 2, pp. 289-314, 2014

DOI: https://doi.org/10.28998/2179-5428.20140204 


\title{
Participação de mulheres no cenário eleitoral brasileiro: questões e explicações na ciência política
}

Palavras-chave: Eleição de mulheres. Determinantes do voto. Ciência Política brasileira. Teoria Social.

\begin{abstract}
In discussions about the female presence in politics are common arguments that explain the low participation of women due to structural constraints, demonstrating that on the established social standards causal are located the determinants of this phenomenon, so that the domination of men over women in private space be reproduced in the public space. This article seeks to identify how this discussion is present in the explanations about the election of women in the Brazilian political scene, presenting the main arguments used in the light of Social Theory. Also shows how the literature about the determinants of voting in Political Science makes analysis about the choice of women in Brazilian elections, considering that contemporary studies bolster on several assumptions of neoinstitutionalism and the Theory of Rational Choice. In this perspective, this work intends to present new perspectives to discuss the election of women which begin to emerge from the gaps in traditional analyzes of the phenomenon.
\end{abstract}

Keywords: Election of women. Determinants of voting. Brazilian Political Science. Social Theory.

\section{Introdução}

O presente trabalho pretende apresentar de que forma a eleição de mulheres no cenário político nacional tem sido analisada na Ciência Política brasileira, com amparo na Teoria Social, sobretudo na literatura que versa sobre os determinantes do voto. O fenômeno da eleição de mulheres, nas diversas esferas de poder, tem merecido um grande número de abordagens em todo mundo. Nesse sentido, questionamos: como a Ciência Política brasileira procurar explicar a escolha de mulheres no contexto eleitoral do país? Quais os principais pressupostos adotados nessas explicações? Esses pressupostos largamente utilizados ao longo da história conseguem se manter atuais para explicar a eleição de mulheres no cenário político e social? 


\section{Priscila Lapa \\ Jamerson Kemps}

Estudos oriundos das Ciências Sociais têm procurado explicar a participação política das mulheres a partir da definição do seu papel social (MIGUEL, 2001). Foi a partir da contestação do princípio liberal da autoidentificação do interesse que nos anos 1970 e 1980 surgiram argumentos em favor da "valorização da diferença" (destaque nosso), eclodindo os discursos da necessidade de paridade da representação feminina e masculina no âmbito da política. Esses discursos procuraram se legitimar com a construção de argumentos que afirmam alguns tipos de diferenças entre homens e mulheres, entre elas a diferença de tipo moral, de interesses e estrutural ${ }^{3}$.

Nas Ciências Sociais também se faz presente uma linha de investigação acerca da representação feminina que busca explicações institucionais para a questão da sub-representação política das mulheres em países como o Brasil. Nesse âmbito de reflexão, as explicações são fundamentadas a partir da análise dos sistemas eleitoral e partidário, entendendo-se que os partidos políticos têm um papel fundamental na organização das demandas institucionais quanto ao ingresso dos cidadãos e cidadãs na vida política de um país (ÁLVARES, 2008).

Diante disto, nos preocupamos em desenvolver uma revisão da teoria social a respeito da relação entre agência e estrutura, tendo em vista que vem sendo utilizada como norte argumentativo sobre a eleição feminina e problematizando-a de acordo com a análise das condições e variáveis sociais que envolvem a mulher brasileira em termos de participação no contexto político.

Em seguida, procuramos enfocar as variáveis explicativas sobre a eleição de mulheres a partir da consideração de elementos determinantes do voto. Utilizamos como ilustração a candidatura de Dilma Rousseff e de Marina Silva à presidência da República em 2010, buscando verificar a presença de análises que questionam se, de fato, estaria havendo uma emergência das mulheres no cenário eleitoral brasileiro, a partir da observação do comportamento das eleitoras brasileiras em relação às suas intenções de voto.

\footnotetext{
${ }^{3}$ Em Política de interesses, política do desvelo: representação e singularidade feminina (MIGUEL, 2000), o autor percorre os argumentos que estruturam os discursos favoráveis à adoção da política de cotas nos sistemas eleitorais ocidentais.
} 


\section{Participação de mulheres no cenário eleitoral brasileiro: questões e explicações na ciência política}

\section{Dominação no espaço privado, consequências para o espaço público: o predomínio das explicações que dão ênfase à estrutura}

A representação feminina na política, nas mais diversas esferas do poder, pode ser interpretada a partir do entendimento de padrões sociais estabelecidos, nos quais estão localizados os determinantes causais desse fenômeno. As bandeiras dos movimentos feministas têm como uma das ideias centrais a importância da esfera privada como espaço privilegiado de dominação e opressão. A opressão das mulheres se expressa no mundo privado na direção do espaço público (MATOS, 2010).

Nesse sentido, o que explicaria, de acordo com os adeptos desse viés interpretativo, a baixa representação feminina seria a existência de uma "fragilidade" social das mulheres em razão da permanência, no contexto atual, de condições de desigualdade entre os gêneros. Algumas questões são tratadas nos debates como evidências dessa fragilidade: desvantagens salariais, sobrecarga de trabalho, responsabilidade quase que exclusiva com a criação dos filhos e cuidados com a família, "sendo esta, de modo quase onipresente, uma das principais 'experiências' do feminino que as sociedades reconhecem e legitimam" (ibidem, p.15). Todos esses aspectos, em princípio, contribuiriam para que a mulher ocupe menos espaços no sistema representativo.

Trazendo essa explicação para os marcos do debate agência $\mathrm{x}$ estrutura, pode-se apontar a influência da estrutura (meio social onde ocorrem relações desiguais entre os gêneros) sobre a agência (a mulher enquanto agente político). Dito de outra forma, os condicionantes estruturais de desigualdade moldam e interferem na capacidade de ação política da mulher (agência). Nesse caso, ressaltam-se os poderes causais da estrutura: no caso das mulheres, haveria uma interferência negativa maior da estrutura do que sobre os homens. Considera-se que o agente masculino age em uma estrutura onde predominam padrões estruturais masculinos, enquanto que o agente feminino deve atuar em uma estrutura favorável aos homens.

Na política, isso seria um obstáculo à ação das mulheres, pois esse espaço seria formatado como sendo um "universo masculino", com seu caráter agressivo (inerentemente masculino), em contraste com o "pensamento maternal" típico das mulheres (MIGUEL, 2001) ${ }^{4}$.

${ }^{4} \mathrm{O}$ autor discorre sobre isso ao referir-se à "política do desvelo" (care politics), que 
Nesse sentido, Pierre Bourdieu discorre sobre essa representação dos papeis e ideais masculinos e femininos na obra $A$ dominação masculina e nos serve como referência de análise. De acordo com ele,
a visão androcêntrica é assim continuamente legitimada pelas próprias práticas que ela determina: pelo fato de suas disposições resultarem da incorporação do preconceito desfavorável contra o feminino, instituído na ordem das coisas, as mulheres não podem senão confirmar seguidamente tal preconceito (BOURDIEU, 2002, p. 22).

A dominação masculina, no entender do autor, é fruto da primazia universalmente concedida aos homens e se afirma na objetividade de estruturas sociais e de atividades produtivas e reprodutivas. Essas estruturas têm como base a divisão sexual do trabalho de produção e de reprodução biológica e sexual. Moldadas dessa forma, funcionam como matrizes das percepções, dos pensamentos e das ações de todos os que compõem a sociedade, "como transcendentais históricos que, sendo universalmente partilhados, impõem-se a cada agente como transcendentes". (idem, p.23).

Fica evidente, portanto, nessa linha de argumentação, que o espaço de atuação da agência tem como alicerce, estruturas que vão além da vontade e das escolhas individuais. Assim, não se pode esperar, no âmbito da política, um comportamento destoante em relação ao padrão de androgenia estabelecido na sociedade:

as próprias mulheres aplicam a toda a realidade e, particularmente às relações de poder em que se veem envolvidas, esquemas de pensamento que são produto da incorporação dessas relações de poder e

\footnotetext{
pressupõe que as mulheres trazem um aporte diferenciado à política, por estarem acostumadas a cuidar do outro e a velar pelos mais indefesos. Nessa visão, com uma presença feminina mais expressiva nas esferas do poder, haveria o abrandamento desse caráter agressivo inerentemente masculino (MIGUEL, 2001, p. 259).
} 


\section{Participação de mulheres no cenário eleitoral brasileiro: questões e explicações na ciência política}

que se expressam nas oposições fundantes da ordem simbólica. (ibidem, p.23).

Tendo em vista esse condicionante estrutural na agência, pode-se compreender que a representação política feminina representaria a negação do padrão constituído socialmente. "Simbolicamente voltadas à resignação e à discrição, as mulheres só podem exercer algum poder voltando contra o forte a sua própria força, ou aceitando se apagar, ou, pelo menos, negar um poder que elas só podem exercer por procuração" (BOURDIEU, 2002, p. 21). Ou seja, as mulheres que chegam ao poder sob essa influência de uma estrutura masculinizada terminam por não representar os interesses das mulheres e tendem a reproduzir o padrão masculino.

Em países como o Brasil, a pesquisa sobre o impacto de mulheres em governos ainda é uma área de investigação nova (MATOS, 2010). O que se sabe, a partir de estudos realizados em outros países, como a Índia, é que o simples fato de haver um maior número de mulheres em governos não vai garantir sua eficácia como defensoras dos interesses e direitos das mulheres. O desafio seria, portanto, o de se desconstruir os lugares socialmente legitimados para seu trabalho e demonstrar capacidade de agir politicamente em diversos âmbitos, "rompendo com os papeis de gênero tradicionalmente rígidos que se reatualizam nos espaços de trabalho político" (ibidem, p.17).

A influência de fatores históricos e institucionais também compõe uma agenda de pesquisa acerca da representação feminina (ARAÚJO, 1998; DIAMOND \& HARTSOCK, 1981; NORRIS \& INGLEHART, 2000). Ao final do século $X X$, no mundo ocidental, a paridade dos sexos na representação política já era quase unanimemente vista como um objetivo justo (MIGUEL, 2001). Em boa parte das democracias representativas, vigoram atualmente leis para incentivar e garantir a presença das mulheres nos centros decisórios, como no caso brasileiro a Lei no 9100/95.

A defesa da extensão dos direitos políticos às mulheres se sustenta na afirmação da igualdade fundamental entre os sexos, ao menos quanto à capacidade de participar do debate público e promover os próprios interesses. Nesse caso, a garantia do aumento da representação feminina traria consequências para os resultados políticos, como a aprovação de um maior número de políticas voltadas para a defesa dos interesses das mulheres. 
Outros vieses estão implícitos nessa discussão, como, por exemplo, a questão da representação de interesses, que procura abordar até que ponto as mulheres compõem uma categoria com interesses idênticos e se porventura esses interesses e objetivos só poderiam ser alcançados por meio da representação feminina. A discussão é extensa e extrapola os intentos deste artigo.

Observando-se contemporaneamente esse debate, emerge a questão: a condição desvantajosa da mulher no contexto social, que dificulta o acesso a estruturas masculinizadas, interfere de que forma na escolha eleitoral? Indo mais além, indaga-se: até que ponto a literatura sobre os determinantes do voto, na Ciência Política brasileira, trabalha na perspectiva de tomar a condição "desvantajosa" da mulher como uma variável explicativa para compreender a presença feminina no cenário eleitoral do país?

Antes de adentramos no estado da arte sobre os determinantes do voto, apresentaremos a seguir, de forma sintética, as linhas do debate agência e estrutura, tendo em vista que vem sendo utilizado como norte argumentativo sobre a eleição de mulheres no país.

\section{Teoria Social e a relação Agência X Estrutura}

Se fosse uma questão simples reconciliar ação e coletividades em uma teoria social única, então a discriminação entre esses temas jamais seria cogitada (COHEN, 1999, p 394).

Mesmo tendo a relação que se dá entre indivíduo e sociedade sendo entendida como o principal objeto de estudo das Ciências Sociais, não se pode dizer que exista uma visão homogênea entre os cientistas sociais quanto a essa temática. Vejamos que por um longo período, a estrutura social foi vista como definidora do comportamento dos indivíduos.

Só para tomar como referência os pensadores clássicos, ressalvando que os mesmos não tomavam as relações sociais pelo paradigma agência e estrutura, temos em Émile Durkheim (2005) o entendimento de que a sociedade seria mais do que a soma de seus indivíduos; ela seria o mais importante elo entre forças naturais e morais, enquanto que cada indivíduo seria apenas uma ínfima parte da mesma, membro de gerações anteriores a ele próprio, que já desapareceram e continuarão a desaparecer, 


\section{Participação de mulheres no cenário eleitoral brasileiro: questões e explicações na ciência política}

diferentemente da estrutura social. Essa seria a base para o seu conceito de Morfologia Social: aquilo que indicaria a força das relações estruturais entre as pessoas, a partir dos processos rituais que envolvem indivíduos.

Em termos de influência da estrutura, encontramos no pensamento marxista semelhante entendimento. A partir do estudo histórico-econômico que realizou sobre o sistema capitalista, Karl Marx (1996) criou os conceitos de Infraestrutura e Superestrutura. Com eles, a sociedade passaria a ser comparada a uma construção, na qual as fundações (infraestrutura) seriam representadas pelas forças econômicas, enquanto que a obra em si mesma (superestrutura) representaria as ideias, costumes e instituições da sociedade.

Para Marx, compreender a vida social passa pela consideração de que alguns grupos e indivíduos procuram sempre estar acima uns dos outros através do controle da estrutura social. Nesse sentido, o pensador atenta para o fato de que as ideias dominantes de uma determinada época e sociedade são exatamente o reflexo da ideologia das classes sociais que a dominam.

Será apenas nos trabalhos de Max Weber (2002) que encontraremos como premissa a ideia de que a sociedade não seria algo superior, exterior e coercitivo que determinaria o comportamento dos indivíduos, mas sim o resultado de uma enorme rede de interações interindividuais. Vejamos que, em termos weberianos, a sociedade não é aquilo que pesa sobre os indivíduos, mas aquilo que se veicula entre eles, pois um mesmo meio cultural pode vir a assumir significados diferentes para os diferentes indivíduos que nele estão inseridos.

Nesse sentido, Weber amplia a análise sociológica para além das estruturas totalizantes de uma sociedade e desenvolve o conceito de Ação Social, entendendo que o mesmo explicaria diferenças de comportamento dos indivíduos a partir do modo de assimilação e os diferentes tipos de racionalidade empregados pelos participantes de uma mesma cultura. Considera que tão importante quanto estudar a influência do sistema econômico, também o é a análise dos aspectos religiosos, militares e geográficos, bem como, a administração burocrática dos estados modernos, partidos políticos e todas as organizações sociais que envolvem a participação de indivíduos.

A partir do que foi estabelecido por aqueles cientistas sociais clássicos, destacamos que a análise das relações dos indivíduos em 
sociedade passou a ser interpretada a partir de outras variáveis epistemológicas.

Representante da escola inglesa, Anthony Giddens (2003) analisa as relações sociais em termos de Estruturação e Práxis Social, entendendo que não se poderia negar a força que os processos históricos desenvolvem enquanto influência nas práticas sociais. Para ele, os seres humanos devem ser entendidos diferentemente dos outros animais porque não são biologicamente programados para produzir vida social.

As relações sociais dizem respeito ao 'posicionamento' dos indivíduos no bojo de um 'espaço social' de categorias e vínculos simbólicos. As regras envolvidas nas posições sociais têm normalmente algo a ver com a especificação dos direitos e obrigações pertinentes as pessoas dessas regras, em outras palavras, são particularmente pronunciadas, mas também a eles se aplicam todas as características anteriormente declaradas das regras. (ibidem, p. 89).

Giddens procurou desenvolver essa reflexão a partir do debate com os trabalhos de George Homans (1974), o mesmo que formulou a teoria que ficou conhecida como a Lei de Homans:

Quanto mais os indivíduos interagem, tanto mais se tornam parecidos e tendem a conformar-se a um padrão comum. Em outras palavras, se determinado grupo de pessoas é reunido de modo a ter que interagirem - trabalhando em um mesmo lugar, vivendo no mesmo bairro ou vila -, elas começam a formar um grupo coeso; elas desenvolvem uma cultura de grupo que não existia anteriormente, e inculca seus padrões sobre cada indivíduo (COLLINS, 1999, p. 118).

O que Homans vem alertar mais a frente é exatamente aquilo que Giddens considerou na citação anterior: a coesão social depende de uma 


\section{Participação de mulheres no cenário eleitoral brasileiro: questões e explicações na ciência política}

situação de igualdade entre os membros de um determinado grupo, segundo critérios de identificação social, práticas comportamentais e interesses comuns. Do contrário, a coesão só seria possível pelo exercício da autoridade.

Outra forma de reforçar tal argumento se faz quando Homans toma um agrupamento de trabalhadores em uma fábrica e percebe que os mesmos tendem a trabalhar em torno de meios e objetivos comuns, mas sem identificação coletiva a respeito de seus chefes ou supervisores. Se interagirem com eles será apenas por obediência, tolerância e interesse em recompensas, mas ainda assim, de maneira limitada e não se identificando nem se relacionando mais fortemente com os mesmos.

A razão pela qual os indivíduos se assemelham uns aos outros e, portanto, influenciam uns aos outros, só pode ser explicada pelo fato de que oferecem aos outros, algo que estes consideram gratificante. Esse algo é a recompensa fundamental da aprovação social. [...] Quando uma pessoa possui o poder de dar ordens, as outras pessoas a evitam, uma vez que esse tipo de interação não traz recompensas. Ambos os tipos de evidência são enquadradas no mesmo princípio: as pessoas pautam suas interações conforme as condições que garantem as melhores recompensas (ibidem, p. 119).

Cada vez mais, a teoria social passa a considerar a perspectiva dos indivíduos nas relações sociais, e neste contexto, Herbert Blumer (1998) preocupou-se em analisar as variadas e indefinidas formas que as relações sociais podem assumir. Esse representante do Interacionismo Simbólico entendia que as pessoas nem sempre adotam papéis sociais préestabelecidos, sendo a sociedade não uma estrutura, mas um processo contínuo de construção da realidade. Sua análise se pautava em três premissas:

1) "the human beings act toward things on the basis of the meanings that the things have for them;2) the of such things is derived from, or arises out of, the social interaction that one has with one's fellows; and 3) the 


\section{Priscila Lapa \\ Jamerson Kemps}

these meanings are handled in, and modified through, an interpretative process used by the person in dealing with the things he encounters" (idem, p. 2).

Foi a partir das premissas da corrente interacionista que o psicólogo social Erwin Goffman (2007) analisou os processos de interação social no seu cotidiano a partir de uma abordagem do tipo microinteracionista de perspectiva dramatúrgica (COLLINS, 1999). Gofmman usa o teatro como metáfora e apoio para o entendimento das interações sociais e suas impressões, o que ele chama de representação do Eu. A partir da análise da interação social, o autor ilumina as representações individuais e o controle consciente e inconsciente, proposital ou displicente, das impressões sobre nós e sobre os outros.

O desempenho dos papéis sociais teria a ver com o modo como cada indivíduo concebe a sua imagem e pretende mantê-la. A pertença a uma classe social, por exemplo, se marcaria através de ritualizações que distinguem indivíduos e grupos, considerando-se aspectos sutis como as formas de se vestir ou de se apresentar publicamente. O pensador diz que "nós realizamos performances, mas elas exigem a utilização de um figurino e de um cenário reais: roupas, o palco, uma plateia e um lugar onde os atores podem guardar seus equipamentos" (idem, p. 191).

Exemplo disso é a relação da vitrine de uma loja (palco), ponto de atração do cliente, com a parte de trás do balcão de vendas (bastidor), local onde os vendedores dividem seus territórios de atuação, estabelecem porcentagem de vendas e se comportam de maneira mais informal. Essa analogia também foi desenvolvida a respeito da relação entre trabalhadores e administradores de fábricas, quando se percebeu que os operários produziam um específico tipo de desempenho ao se perceberem supervisionados, mas que desempenhavam outra, mais informal, quando se encontravam apenas entre si.

Sobre este contexto, a análise goffmaniana ainda nos traz a ideia de Frame. Nela, mesmo que o mundo se torne bastante complexo, o mesmo tende a ser edificado a partir da repetição de um pequeno número de mecanismos reflexivos pautados em marcos primários. Para Goffman (2006), o frame, ou enquadramento, seria a análise de algum tipo de acontecimento dentro de um marco de referência composto por relações culturais que se dão entre agentes e forças sociais, pois mesmo os 


\section{Participação de mulheres no cenário eleitoral brasileiro: questões e explicações na ciência política}

acontecimentos soltos no mundo social, podem ser apreendidos a partir da instrumentalização analítica com base em frames.

Mesmo que por algum motivo haja a quebra desse enquadramento, pode-se analisar a nova situação a partir de novos enquadramentos que se estendam às circunstâncias que possibilitaram e criaram essa situação inusitada.

Por sua vez, Piotr Sztompka (2005) destaca que a vida social é regulada por regras, normas, valores e instituições que regulam a conduta humana, e neste contexto, apresenta a organização social como aquilo que "se baseia em normas coletivamente reconhecidas e aceitas, que regulam não só as ações como também as experiências e representações de seus membros" (idem, p. 423). O pensador polonês tem como finalidade provar a possibilidade de modificação das estruturas normativas citadas, a partir do que chama de Transgressão Institucionalizada de Regras. Para o autor, a mudança pode ser produzida de maneira incremental ou de maneira peremptória, por agentes que empreendem uma reforma normativa na vida cotidiana das pessoas comuns e nas organizações com as quais se relacionam.

Analisando a dicotomia entre agência e estrutura, Stompka vale-se do conceito de Norbert Elias (1994) sobre Figurações: aquilo que se apresenta como relações complexas de interdependência e que cobrem o hiato entre ação e estrutura, uma vez que os indivíduos constituem figurações históricas e são historicamente constituídos por eles.

Para Elias, o indivíduo e a sociedade são indissociáveis e interdependentes. Em seus trabalhos, o pensador descreve a ideia de que a sociedade não poderia ser vista apenas como a soma de vários indivíduos, assim como o indivíduo não deveria ser entendido como determinado totalmente pela sociedade. Na medida em que as sociedades se tornam mais complexas, mais desenhos de normas sociais se apresentam e por consequência, se evidenciam mais possibilidades de se entender como indivíduo, pois será a historicidade de cada um deles aliada ao fenômeno do crescimento até a fase adulta, a chave para a compreensão do que seria sua sociedade.

Também destacamos em Elias, o seu entendimento sobre a ideia de Nós: pronome coletivo, mas também emaranhado de relações interpessoais. O sociólogo alemão leva em consideração a formação histórica e trajetória social de cada indivíduo enquanto possível agente, e assim como Foucault 
e Bourdieu, leva em conta a posição social de poder associada ao indivíduo. Para ele, "não há identidade-eu sem identidade-nós" (idem, p. 152).

Com base no que fora refletido por Elias, Piotr Sztompka nos leva a considerar o que seria uma análise das relações sociais de nível intermediário, uma vez que "não existem agentes sem estruturas nem estruturas sem agentes, ao mesmo tempo em que as estruturas não se dissolvem nos agentes e os agentes não se dissolvem nas estruturas" (2005, p. 368).

Ainda sobre o campo da ciência social, Georg Simmel percebe que há um problema particular: em detrimento da sociedade, o indivíduo é tido como algo concreto e por isso foco central de análise, enquanto que à sociedade seria dado um papel secundário.

Em Questões fundamentais da Sociologia (2006) questiona: seria a sociedade objeto da existência humana ou simplesmente um meio para o indivíduo? Para o autor, indivíduo e sociedade devem ser pensados de forma única, sendo importante para sua análise, os processos sociais subjacentes à Sociação. Para Simmel, sociação "significa antes de tudo, relação/interação entre os indivíduos em seu cotidiano" (FONTES, 2012 p. 102). Essa concepção entende que nem a sociedade determina todas as relações de maneira onipotente, mas que também, os indivíduos não podem ser tomados como determinantes exclusivos.

Para a sociologia simmeliana, o processo de complexificação das sociedades causa a perda de vínculos comunitários. A sociedade representaria aquilo feito pelos indivíduos para os indivíduos a partir de laços de interação que de maneira contínua são desfeitos e renovados (limitados ou expandidos) em um contínuo processo de sociação. “A sociedade, então, é estudada a partir da forma como os diversos fenômenos se estruturam" (ibidem, p. 101), ${ }^{5}$ cabendo para sua análise à adequação de um método pertinente às realidades sociais específicas, definindo categorias de análise que deem conta de modos formais de comportamento, tais quais, interações sociais influenciadas por relações de poder, status e divisão de trabalho (SIMMEL, idem, p. 09).

\footnotetext{
${ }^{5}$ Breno Fontes (2012) esclarece que o conceito simmeliano de formas é entendido como estruturações mais perenes e constitutivas de fenômenos de mesma natureza, mas que se manifestam, em inumeráveis ocasiões, sob condições particulares.
} 


\section{Participação de mulheres no cenário eleitoral brasileiro: questões e explicações na ciência política}

A respeito da citada consideração sobre a pertinência da escolha do método, encontramos no trabalho de John Elster (1989) o entendimento de que o cientista social deveria voltar sua atenção para aqueles processos do plano individual que possam explicar os fenômenos sociais - sua estrutura e mudança - de modo que só envolvam indivíduos em suas propriedades, objetivos, crenças e ações.

Com enfoque voltado para a análise e descrição dos mecanismos que constituiriam a essência dos fenômenos sociais, o filósofo propõe um sistema metateórico que possa dar conta dessa explicação a partir do Individualismo Metodológico. Com ele, devem-se oferecer explicações intencionais-causais para os fenômenos estudados, aliando a explicação intencional das ações individuais com a explicação causal da interação social.

Em sua Explicação por Mecanismos, Jon Elster procura invocar o agente causal, ou seja, os atores individuais, fazendo referência às causas e consequências das ações desses indivíduos, abrindo-se a caixa-preta colocada entre o que é causa e o que é efeito (RATTON, 2002).

Em seu método de Reducionismo Explicativo, Elster parte da observação de instituições sociais e padrões agregados de comportamento para a observação específica de indivíduos, primando pela capacidade de reduzir fenômenos complexos e seus elementos constitutivos às ações individuais. Em sua obra Sour Graves (1983), ele levanta questões sobre como as instituições tomam decisões e se elas pensam tal qual um indivíduo, entendendo que os mecanismos destas relações podem estar separados, mas que em seu âmbito terminam por agir conjuntamente.

Por fim, podemos refletindo a respeito das práticas de individualização e socialização dentro de ambientes institucionais. Devemos tomar a individualização, processo que diferencia os indivíduos, como parte constituinte da socialização que dissemina as normas sociais, enquanto que a socialização pode ser definida como um amplo processo de introdução de um indivíduo no mundo objetivo e subjetivo de uma sociedade ou de um setor dela (BENZAQUEN, 2007).

Temos que dessa forma, o processo de socialização depende da estrutura social na qual o indivíduo se encontra, mas que também é influenciado pela individualidade de casa pessoa, ou seja, pelo seu corpo, pelas suas formas cognitivas únicas e pelas suas experiências anteriores, já 
que "o indivíduo tem um modo particular e específico de dialogar com as estruturas sociais" (idem, p. 51).

Na medida em que precisam conviver cotidianamente dentro de um mesmo espaço institucional, os indivíduos procuram estabelecer padrões de comportamento que estejam voltados as suas práticas e interesses. Já de maneira inversa é a instituição que procura se sobressair e aplicar sobre os seus indivíduos, práticas de socialização organizacionais voltadas ao atendimento e cumprimento de suas metas e objetivos.

\section{Os indivíduos e as instituições sob a ótica do Neoinstitucionalismo}

Fenômenos sociais, como a representação e o voto feminino, também podem ser compreendidos com o amparo do neoinstitucionalismo, em suas três versões (o institucionalismo histórico, o sociológico e o da escolha racional) que não necessariamente são contraditórias. A análise de Hall e Taylor (2003) das três versões do novo institucionalismo é feita com base em duas questões: (i) como construir a relação entre instituições e comportamento e (ii) como explicar o processo pelo qual as instituições surgem e se modificam. Por isso, faz-se essencial revisar brevemente o que preconizam essas escolas.

De acordo com os autores, o institucionalismo histórico se caracteriza por recorrer tanto à perspectiva do cálculo quanto à da cultura, no que diz respeito ao comportamento dos indivíduos quando confrontados com instituições. Os seus adeptos defendem também a ideia da distribuição assimétrica do poder, em especial de como as instituições repartem o poder de maneira desigual entre grupos sociais.

Do ponto de vista da causalidade social, esta versão apresenta uma causalidade dependente da trajetória percorrida, denominada de path dependence. Isto implica assumir que as instituições são entendidas em termos de suas propriedades herdadas do passado, e não apenas como a escolha dos indivíduos no momento em que a ação acontece.

Os institucionalistas históricos defendem que as instituições não são consideradas como o único fator que influencia a vida política, o que significa que instituições estão sempre combinadas com outros fatores na cadeia causal (SANTOS, 2006). Já o conjunto de atributos que caracteriza o institucionalismo da escolha racional parte do pressuposto de que os atores compartilham um conjunto determinado de preferências e se comportam 


\section{Participação de mulheres no cenário eleitoral brasileiro: questões e explicações na ciência política}

de modo utilitário, no sentido de maximizar a satisfação de suas preferências.

Essa maximização se dá pela ação estratégia, que pressupõe um número significativo de cálculos. Deriva deste pressuposto que os institucionalistas da escolha racional tendem a considerar a vida política como uma série de dilemas de ação coletiva, em que os atores procurando seus interesses podem chegar a resultados subótimos para a coletividade (HALL e TAYLOR, 2003).

Os defensores do institucionalismo sociológico, em sua definição de instituições, incluem não apenas regras, procedimentos ou normas formais, mas também os sistemas simbólicos, os esquemas cognitivos e os modelos morais que fornecem "padrões de significação" que guiam a ação humana.

$\mathrm{Na}$ verdade, há uma ruptura com a dicotomia entre instituições e cultura, uma vez que cultura é redefinida como sinônimo de instituições (SANTOS, 2006). Isto significa que o enfoque assume uma forte dimensão normativa do impacto das instituições, ou "dimensão cognitiva", das instituições na ação humana.

Um ponto de convergência entre as três versões acima descritas é que todas elas buscam compreender como diferentes resultados sociais são produzidos a partir de diferentes arranjos institucionais. Dito de outra maneira: "quando, como, e em que condições instituições importam para explicar fenômenos sociais e políticos?" (LIMONGI, 2004).

Os cientistas políticos que focam em suas análises as escolhas eleitorais utilizam como referência as chamadas escolas do comportamento eleitoral que, em grande parte, se amparam nos pressupostos adotados pela Ciência Política contemporânea acima descritos.

\section{O que diz a literatura da Ciência Política sobre os determinantes do} voto As razões que levam um eleitor a decidir por um dos candidatos em uma arena eleitoral compõem o que a Ciência Política compreende como sendo os determinantes do voto. Assim, os cientistas políticos tratam os determinantes do voto como fenômenos sociais a serem compreendidos e explicados, especificando-se as relações de variáveis, as quais expressam mecanismos que lhe dão vida (VAN EVERA, 1997; ELSTER apud OLIVEIRA, 2011). Temos que as ações sociais dos indivíduos geram os fenômenos sociais. De acordo com Raymond Boudon: 
O primeiro princípio fundamental da sociologia da ação consiste em levar a sério o fato de que todo fenômeno social, qualquer que seja, é sempre o resultado de ações, atitudes, de convicções, e em geral de comportamentos individuais. $\mathrm{O}$ segundo princípio, que completa o primeiro, afirma que o sociólogo que pretende explicar um fenômeno social deve procurar o sentido dos comportamentos individuais que estão em sua origem (1995, p. 28).

Além dessa compreensão da ação social, os estudos contemporâneos acerca dos determinantes do voto amparam-se, em grande medida, em diversos outros pressupostos do Neoinstitucionalismo e da Teoria da Escolha Racional, em relação ao papel desempenhado pelas instituições na determinação de resultados sociais e políticos.

A literatura acerca dos determinantes do voto condensa as investigações em quatro escolas: Teoria Psicológica; Teorias Sociológicas e Economicistas; Teoria da Escolha Racional e Modelo Demográficodescritivo (FIGUEIREDO, 1991).

Na corrente sociológica, as decisões de voto são comandadas por identidades sociais, resultantes de interesses. Esses interesses são formados a partir da inserção dos indivíduos em processos coletivos. Nesse modelo, são exploradas as articulações entre voto e gênero, renda e a escolaridade do eleitor (TELLES, LOURENÇO, STORNI, 2009).

Para a Teoria Psicológica, conhecida como o Modelo de Michigan, o comportamento dos indivíduos é função da interação das atitudes a que esses indivíduos estão sujeitos em suas experiências sociais e políticas. A convergência de atitudes frente ao mundo é o ingrediente básico para a compreensão do fenômeno social em sua totalidade (FIGUEIREDO, 1991). A decisão do eleitor está relacionada às suas motivações, inclinações ou predisposições psicológicas, ao contrário da classe e da origem social (conforme preconiza a teoria sociológica).

De acordo com os pressupostos da escolha racional, o eleitor downsoniano ${ }^{6}$ é racional sempre que escolher entre as alternativas

${ }^{6}$ Referência à obra de Anthony Downs (1999). 


\section{Participação de mulheres no cenário eleitoral brasileiro: questões e explicações na ciência política}

eleitorais aquela que esteja melhor posicionada no seu ranking de preferências em detrimento das demais. Ele se preocupa com as políticas públicas, avaliava o desempenho dos governos e a personalidade dos postulantes aos cargos executivos.

As situações de escolha dos indivíduos são condicionadas por quatro elementos: (i) os objetivos desejados (os propósitos que motivam a ação); (ii) as crenças sobre a adequação dos meios que devem ser racionalmente formadas de acordo com as evidências disponíveis; (iii) os elementos físicos, econômicos e institucionais que formam e restringem as alternativas; (iv) as ações das outras pessoas, se estas interferirem, endogenamente, na adequação dos meios disponíveis.

Nessa perspectiva teórica, o eleitor vota como um juiz, avaliando os resultados políticos e econômicos, punindo o governo, quando as coisas estão mal, e apoiando-o, quando as coisas estão bem (TELLES, LOURENÇO e STORNI, 2009).

$\mathrm{O}$ ato de votar é, portanto, uma forma de penitenciar ou de recompensar os partidos. Na verdade, há uma combinação de avaliação pelo eleitor: a avaliação do passado o ajuda a fazer projeções para o futuro acerca daquele partido ou candidato. O que a teoria espera explicar é que as avaliações positivas do desempenho político-econômico atuem no sentido de aumentar as possibilidades de voto na situação, ao passo que percepções negativas beneficiem a oposição ao governo.

\section{Os determinantes do voto na Ciência Política brasileira}

A Ciência Política brasileira utilizou como base esses estudos acerca do eleitorado norte-americano para conduzir as análises sobre o eleitor brasileiro. Por isso, por aqui também predominou por muito tempo a premissa de "o povo não sabe votar", ou seja, os eleitores brasileiros parecem não ter fortes opiniões sobre assuntos políticos cruciais.

Estudos como o de Silveira (1998) descrevem o eleitor brasileiro como "irracional", logo incoerente e desarticulado para tratar de assuntos políticos. As escolhas eleitorais seriam, dessa forma, baseadas no personalismo, nas características dos próprios candidatos, como honestidade e imagem.

A predominância do clientelismo nas relações Estado-sociedade no Brasil também está subjacente à percepção de que os cidadãos não 
politizam temas de importância nacional (WEYLAND, 1996; HAGOPIAN, 1996; VON METTENHEIM, 1995).

O conflito político estaria centrado na disputa por recursos públicos limitados e benefícios pessoais, tais como água potável, ruas calçadas e, sobretudo, empregos no setor público. O voto, assim, seria racional (e economicamente autointeressado), mas os eleitores não estariam voltados para os debates públicos, sobretudo aqueles de importância nacional.

Recentemente, alguns estudiosos do comportamento político do eleitorado brasileiro tem tentado "resgatar" o eleitor brasileiro, a partir de um modelo retrospectivo racional (BAKER, 2002). De acordo com os autores dessa vertente, existem fortes e convincentes evidências de haver um eleitor racional que baseia sua escolha eleitoral na avaliação do desempenho dos políticos no exercício do mandato.

Argumenta-se que, por exemplo, o Plano Real foi decisivo para a vitória de Fernando Henrique Cardoso (TEIXEIRA MENDES, VENTURI, 1994; MENEGUELLO, 1996; ALMEIDA, 1996), da mesma forma que essa variável (Plano Real) explica a aprovação presidencial (CHAFFEE, 1998). Mas é possível evidenciar, de acordo com esse exemplo, a existência de votos orientados por tema (issue voting) no Brasil?

Baker (2002) aponta evidências de que os brasileiros politizam os debates sobre política econômica, com base em dados de um survey realizado em janeiro de 1998, demonstrando as atitudes do eleitorado com relação à privatização, investimento estrangeiro e liberalização do mercado, e sua influência sobre a avaliação presidencial.

Nesse sentido, se faz pertinente a observação de Carreirão (1999) de que a avaliação do desempenho geral do governo deve depender de outras variáveis, mas ela é muito influenciada pela avaliação feita pelos eleitores das políticas econômicas dos governos, materializadas por meio dos planos econômicos.

Esta avaliação - que é subjetiva - tem uma correspondência com aspectos centrais da situação efetiva da economia. Boa parte do eleitorado, de acordo com essa visão, vota para presidente buscando melhorias econômicas para si e para o país. A questão que se segue é como essa avaliação é feita pelo eleitor: que aspectos influenciam nesse processo? (entre eles os meios de comunicação). 


\section{Participação de mulheres no cenário eleitoral brasileiro: questões e explicações na ciência política}

Lavareda (2009) analisa que o clima positivo (variáveis emocionais) gerado pela economia tem reflexo na escolha do eleitor nas eleições municipais e, em proporção ainda maior, nas eleições para presidente da República. Segundo o autor, ainda carecemos na Ciência Política brasileira de estudos que possam apontar que variáveis emocionais (ou estados de ânimo) poderiam influir na formação dessa atitude otimista do eleitor brasileiro acerca das questões econômicas.

Considerando as eleições presidenciais de 1989, 1994 e 1998, Carreirão (2002) aponta que a imagem política, os atributos pessoais dos candidatos e o desempenho do governo em exercício, em particular na área econômica, são alguns fatores que definem a escolha do eleitor.

O papel das emoções na escolha do eleitor vem ganhando destaque na Ciência Política brasileira, com autores como Lavareda (2009) e Pimentel Júnior (2010), abrindo um diálogo entre escolha racional e emoção. A hipótese é de que ingredientes como entusiasmo e ansiedade atuam no processo de escolha: eleitores entusiasmados estão predispostos a votar em determinado candidato. A ansiedade do eleitor representaria a reflexão quanto às vantagens e desvantagens de escolher algum candidato.

Grande parte dessas novas tendências acerca dos estudos eleitorais, de certa forma, aponta uma mudança nas visões acerca dos determinantes do voto, com o desuso de variáveis tradicionais "identidade ideológica" e "identidade partidária".

As conclusões apresentadas por Singer (2000) sobre os determinantes do voto nas eleições presidenciais de 1989 e 1994, que seriam, para o autor, a identidade ideológica do eleitor, estariam sendo amplamente invalidadas para explicar os resultados eleitorais na atualidade. Variáveis como a conjuntura econômica e o desempenho dos candidatos têm sido amplamente consideradas.

A variável "gênero", conforme brevemente revisado acima, não desponta como objeto de estudo em grande parte das explicações atuais acerca das escolhas dos eleitores. Uma das questões a serem investigadas é: há uma diferença significativa, por exemplo, de necessidades e expectativas entre os eleitores masculinos e femininos? E mais: as mulheres possuem "autonomia" para realizar suas escolhas e capacidade de influenciar na decisão do voto?

Algumas análises da eleição presidencial brasileira de 2010 - a primeira com duas candidatas mulheres efetivamente competitivas - 
procuraram demonstrar as preferências pelos candidatos levando em consideração o gênero do eleitor, ou seja, como votaram os homens e as mulheres naquele pleito. Um pressuposto básico de análise é que "não necessariamente mulher vota em mulher" (ALVES; PINTO e JORDÃO, 2012).

Uma visão pioneira na Ciência Política busca apresentar as percepções da opinião do eleitorado brasileiro no contexto daquela eleição. Um dos argumentos investigados é se a presença tímida de mulheres nos cargos executivos e legislativos no Brasil reflete a postura refratária do eleitorado com relação a elas (idem, ibidem). Segundo essa linha explicativa, um dos obstáculos às mulheres na política seria a visão do eleitorado de que as mulheres não são aptas a atuarem na arena políticoinstitucional como os são os homens.

Também começam a ganhar destaque na agenda pesquisas que tomam como pressuposto o argumento de que as características pessoais de eleitores/as e candidatos/as, entre outras, influenciam as escolhas que os votantes fazem de suas candidatas e candidatos (CAVENAGHI; ALVES, 2012).

A análise dos dados relativos às eleições de 2010, por exemplo, feita por Alves (2012), permitiu que ele interpretasse que as mulheres seriam mais exigentes e gostariam de conhecer melhor as candidaturas. "Da mesma forma que as mulheres são consumidoras mais exigentes e cuidadosas, elas só definem o voto quando são convencidas das qualidades pessoais e programáticas das candidaturas" (ALVES, idem, p. 41)7.

Visualizando-se os dados de intenções de voto, a candidata Dilma Rousseff manteve melhor desempenho no eleitorado masculino do que no feminino, enquanto que José Serra e Marina Silva apresentaram melhor resultado entre as mulheres. Para o autor, esta diferença foi responsável pela existência do segundo turno nas eleições presidenciais de 2010, da mesma forma como tinha ocorrido nas eleições de 2002 e 2006 (ALVES, 2010). A candidata do PT venceu as eleições, no segundo turno, tanto entre os homens quanto entre as mulheres, mas com uma margem maior entre os primeiros.

${ }^{7} \mathrm{O}$ autor chega a essa interpretação ao constatar que nas eleições de 2010 foi confirmada uma tendência recorrente nas eleições presidenciais do Brasil, durante a Nova República, que é o maior percentual, entre as mulheres, de intenções de votos brancos, nulos, nenhum e não sabe. 


\section{Participação de mulheres no cenário eleitoral brasileiro: questões e explicações na ciência política}

Em que pese a análise de outras variáveis para explicar os resultados eleitorais e o comportamento do eleitor é importante ressaltar o valor simbólico da escolha de uma mulher para presidir pela primeira vez o Brasil. Nesse sentido, significaria a real inclusão de gênero, ainda que não tenha decorrido do movimento feminista organizado em entidades.

"Mesmo havendo duas mulheres disputando a Presidência da República, a discussão de gênero não fez parte dos assuntos principais da campanha, muito menos a pauta feminista esteve presente" (ibidem, p. 45).

Assim, parece que a Ciência Política tem procurado abarcar outras questões acerca da representação feminina no cenário político nacional, reiterando que há variáveis que vão além da dicotomia entre agência e estrutura por trás desse fenômeno.

\section{Considerações Finais}

Discutir a representação feminina na política utilizando como eixo o debate tradicional, que procura compreender as interações entre o agente e a estrutura, tem sido o caminho mais comum para as explicações acerca do baixo número de mulheres nos parlamentos e na esfera executiva em todo o mundo.

A compreensão, em linhas gerais, é que os condicionantes estruturais atuam com força tal que parece que a agência acaba reproduzindo esses padrões de ação. A possibilidade de romper com os padrões estruturais seria por meio de instituições, com a geração de novos valores, mudanças culturais e novos padrões simbólicos, que demonstrem a capacidade feminina de atuar em um espaço tradicionalmente masculino.

Ainda que possam as mulheres, em um primeiro momento, adotar alguns desses padrões masculinos para ter sucesso em uma disputa eleitoral, mesmo assim, a eleição de mulheres, de acordo com essas explicações, pode servir como incentivo para novas práticas e novas ações que incluam a presença da mulher nas instâncias de poder.

Todavia, levando em consideração que a Ciência Política tem adotado alguns outros caminhos teóricos para explicar as escolhas eleitorais - incluindo conceitos advindos do neoinstitucionalismo e posicionando que as instituições importam, tanto quanto os contextos, também os valores culturais e histórias de vida dos indivíduos - nos parece que novas questões passam a compor a agenda de pesquisa, no entanto não há ainda uma mudança significativa no padrão de interpretação das 
explicações acerca da participação feminina na política, sobretudo nos processos eleitorais.

Uma agenda de pesquisas que fuja um pouco desse eixo da discussão poderá auxiliar a esclarecer, de modo mais preciso, algumas nuances da variável gênero e de que modo ela está relacionada à formulação das preferências dos eleitores (e das eleitoras). Nesse caminho, os estudos que consideram a variável gênero podem encorpar as explicações que partem do pressuposto que as características pessoais e varáveis emocionais de eleitores/as e candidatos/as, entre outras, influenciam as escolhas que os votantes fazem de suas candidatas e candidatos.

\section{Referências}

ÁLVARES, Maria Luzia Miranda. Mulheres brasileiras em tempo de competição eleitoral: seleção de candidaturas e degraus de acesso aos cargos parlamentares. Dados - Revista de Ciências Sociais. Rio de Janeiro, vol. 51, no $4,2008$.

ALVES, J. E. D. Mulheres jogam as eleições para o segundo turno em 2010. O Pensador Selvagem, Florianópolis, 03/10/2010.

; PINTO, C.; JORDÃO, F. (orgs.). Mulheres nas eleições 2010. Rio de Janeiro: ABCP, 2012.

ARAÚJO, Clara. Mulheres e representação política: a experiência das cotas no Brasil. Revista Estudos Feministas, v.6, n.1, 1998.

BAKER, Andy. Reformas liberalizantes e aprovação presidencial: a politização dos debates da política econômica no Brasil. DADOS - Revista de Ciências Sociais, Rio de Janeiro, vol.45, nº 1, 2002, PP. 77-98.

BENZAQUEN, Júlia F. A socialização para cooperação: uma análise de práticas de educação não formal. Recife: Bagaço, NUPEP, 2007.

BLUMER, Herbert. Symbolic Interactionism. Perspective and Method. Los Angeles: California, 1998. 
Participação de mulheres no cenário eleitoral brasileiro: questões e explicações na ciência política

BOURDIEU, Pierre. A dominação masculina. Rio de Janeiro: Bertrand Brasil, 2002.

CAVENAGHI, Suzana; ALVES, José Eustáquio Diniz. Quem vota em quem: um retrato das intenções de voto nas eleições para presidente em setembro de 2010. In: ALVES, J.E.D.; PINTO, C.; JORDÃO, F. (orgs.). Mulheres nas eleições 2010. Rio de Janeiro: ABCP, 2012.

CARREIRÃO, Yan de Souza. A eleição presidencial de 2002: uma análise preliminar do processo e dos resultados eleitorais. Revista de Sociologia e Política, Curitiba, n. 22, p. 179-194, jun. 2004.

COHEN, Ira J. Teoria da Estruturação e Práxis Social in: GIDDENS, Anthony e TURNER, Jonathan. Teoria Social hoje. São Paulo: UNESP, 1999, p. 393-446.

DURKHEIM, Émile. Da divisão do trabalho social. 2 ed. São Paulo: Martins Fontes, 1999.

ELIAS, Norbert. A sociedade dos indivíduos. Rio de Janeiro: Jorge Zahar, 1994.

ELSTER, John. Peças e Engrenagens das Ciências Sociais. Rio de Janeiro: Relume-Dumará, 1989.

Sour Grapes. Studies in the subversion of rationality. Cambridge: University Press, 1983.

FIGUEIREDO, Marcus. A decisão do voto. São Paulo: Sumaré, 1991.

GIDDENS, Anthony. A constituição da Sociedade. 2 ed. São Paulo: Martins Fontes, 2003.

GOFFMAN, E. A representação do eu na vida cotidiana. 14 ed. Petropólis: Vozes, 2007.

Frame Analysis. Los marcos de La experiência. Madrid: Centro de investigaciones Sociológicas, 2006 


\section{Priscila Lapa \\ Jamerson Kemps}

HALL, Peter; TAYLOR, R. C. R. (2003). As três versões do neoinstitucionalismo. Lua Nova, n 58, pp. 193-223.

HOMANS, G. C. Social Behavior. Its elementary forms. New York: Harcourt, Brace, 1974.

LAVAREDA, Antonio. Emoções ocultas e estratégias eleitorais. Rio de Janeiro: Objetiva, 2009.

LIMONGI, Fernando (1994) O novo institucionalismo e os estudos legislativos: a literatura norte-americana recente. BIB - Boletim Informativo e Bibliográfico de Ciências Sociais. n. 37. pp.1-100.

MARX, K. Para a crítica da economia política do capital. São Paulo: Nova Cultural, 1996.

MATOS, Marlise. O que se pode esperar de uma presidência e um governo no feminino? Mais mulheres no poder podem fazer diferença?. Em Debate, Belo Horizonte, v.2, n.12, p.14-21, dez. 2010.

MIGUEL, Luís Felipe. Política de interesses, política do desvelo: representação e "singularidade feminina". Revista Estudos Feministas, ano 9, $2^{\mathrm{o}}$ semestre, 2001.

NORRIS, Pippa e INGLEHART, Ronald. (2000), Cultural Barriers to Women's Leadership: A Worldwide Comparison.Trabalho apresentado no International Political Science Association World Congress, Quebec. Disponível em http://ksghome. harvard.edu/ pnorris, acessado em 26/08/2013.

OLIVEIRA, Adriano. O lulismo e as suas manifestações no eleitorado. Revista Debates, Porto Alegre, v. 5, n. 1, p. 115-138, jan.- jun. 2011.

PIMENTEL JÚNIOR, Jairo Tadeu Pires. Razão e emoção no voto: o caso da eleição presidencial de 2006. 128 f. Dissertação (Mestrado em Ciência Política) - Faculdade de Filosofia, Letras e Ciências Humanas, Universidade de São Paulo, São Paulo, 2007. 
Participação de mulheres no cenário eleitoral brasileiro: questões e explicações na ciência política

RATTON, J. L. e VENTURA, J. Para ler John Elster: limites e possibilidades da explicação por mecanismos nas Ciências Sociais. Dados, 2002.

SANTOS, Manoel Leonardo W.D. (2006). As Teorias Positivas da Organização Legislativa e as Explicações sobre o Congresso Nacional. Dissertação (Mestrado em Ciência Política) - Centro de Filosofia e Ciências Humanas, Universidade Federal de Pernambuco, Recife-PE.

SIMMEL, Georg. Questões fundamentais da Sociologia. Rio de Janeiro: Zahar, 2006.

SINGER, André. Esquerda e direita no eleitorado brasileiro: a identificação ideológica nas disputas presidenciais de 1989 e 1994. São Paulo: Edusp, 2000 .

SILVEIRA, Flavio Eduardo. (1998). A Decisão do Voto no Brasil. Porto Alegre, EDIPUCRS.

STOMPKA, Piotr. A sociologia da mudança social. 2 ed. Rio de Janeiro: Civilização brasileira, 2005

TELLES, Helcimara; LOURENÇO, Luiz Cláudio; STORNI, Tiago Prata L. Partidos, campanhas e voto: como o eleitor decide nas municipais. Sociedade e Cultura, Goiânia, v. 12, n.1, p. 91-116, jan/jun, 2009.

VON METTENHEIM, Kurt. The brazilian voter: mass politics in democratic transition, 1974-1986. Pittsburgh: Pittsburgh University Press, 1995.

WEBER, Max. Ensaios de Sociologia. Rio de Janeiro. Ed. LTC, 2002.

WEYLAND, Kurt. Democracy without equity: failures of reform in Brazil. Pittsburgh: University of Pittsburgh Press, 1996.

Enviado:

28.07.2014

Aprovado:

05.11.2014 